\title{
MASTER
}

\section{Evaluation of ADAM/1 Model for Advanced Coal-Extraction Concepts}

Govind K. Deshpande

Mukund D. Gangal

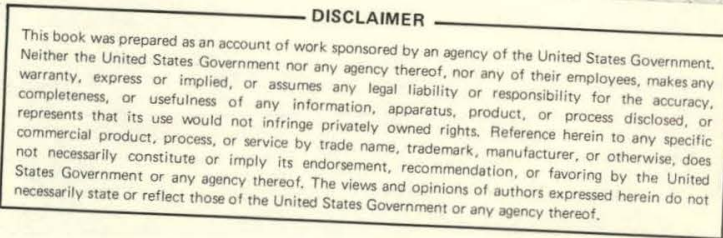

January $15,198 \%$

Prepared for

U.S. Department of Energy

Through an Agreement with

National Aeronautics and Space Administration

by

Jet Propulsion Laboratory

California Institute of Technology

Pasadena, California 


\section{DISCLAIMER}

This report was prepared as an account of work sponsored by an agency of the United States Government. Neither the United States Government nor any agency Thereof, nor any of their employees, makes any warranty, express or implied, or assumes any legal liability or responsibility for the accuracy, completeness, or usefulness of any information, apparatus, product, or process disclosed, or represents that its use would not infringe privately owned rights. Reference herein to any specific commercial product, process, or service by trade name, trademark, manufacturer, or otherwise does not necessarily constitute or imply its endorsement, recommendation, or favoring by the United States Government or any agency thereof. The views and opinions of authors expressed herein do not necessarily state or reflect those of the United States Government or any agency thereof. 


\section{DISCLAIMER}

Portions of this document may be illegible in electronic image products. Images are produced from the best available original document. 
DOE/ET/12548--12

DE82 013330

\section{Evaluation of ADAM/1 Model for Advanced Coal-Extraction Concepts}

Govind K. Deshpande

Mukund D. Gangal

January 15,1982

Prepared for

U.S. Department of Energy

Through an Agreement with

National Aeronautics and Space Administration

by

Jet Propulsion Laboratory

California Institute of Technology

Pasadena, California 
Prepared by the Jet Propulsion Laboratory, California Institute of Technology, for the U.S. Department of Energy through an agreement with the National Aeronautics and Space Administration.

This report was prepared as an account of work sponsored by an agency of the United States Government. Neither the United States Government nor any agency thereof, nor any of their employees, makes any warranty, express or implied, or assumes any legal liability or responsibility for the accuracy, completeness, or usefulness of any information, apparatus, product, or process disclosed, or represents that its use would not infringe privately owned rights.

Reference herein to any specific commercial product, process, or service by trade name, trademark, manufacturer, or otherwise, does not necessarily constitute or imply its endorsement, recommendation, or favoring by the United States Government or any agency thereof. The views and opinions of authors expressed herein do not necessarily state or reflect those of the United States Government or any agency thereof. 


\section{ABSTRACT}

Several existing computer programs for estimating life-cycle cost of mining systems have been evaluated. A commercially available program ADAM/l was found to be satisfactory in relation to the needs of the Advanced Coal Extraction Project. Two test cases were run to confirm the ability of the program to handle non-conventional mining equipment and procedures. The results were satisfactory. The model, therefore, is recommended to the project team for evaluation of their conceptual designs.

Since the model is commercially available, data preparation instructions are not reproduced in this document; instead the reader is referred to the original documents for this information. 
This document was prepared in support of the Advanced Coal Extraction Project at JPL. Evaluation of performance of various advanced mining concepts requires the development and refinement of analytical tools. This document is an evaluation of the ADAM/l coal mining simulation model for applicability to advanced mining concepts.

This effort was made possible by the cooperation of Ketron, Inc., developers of the ADAM/l Model. William Douglas, Jeff Kohler, Kathleen Knoebel, and Jack Urie of Ketron, Inc., helped in the setup of the model for computer processing. Govind Deshpande worked with Ketron and obtained the results for the two test cases.

Milt Lavin and Lon Isenberg assisted in the selection of computer models and provided guidance throughout this evaluation.

This report was published by the Jet Propulsion Laboratory through NASA Task RD-152, Amendment 90, and was sponsored by the U. S. Department of Energy under Interagency Agreement DE-AI01-76ET 12548. 
CONTENTS

1. INTRODUCTION . . . . . . . . . . . . . . . . . . 1

1.1 BACKGROUND . . . . . . . . . . . . . . . . . . 1

1.2 obJectives . . . . . . . . . . . . . . . . 1

1.3 ORGANIZATION OF THE REPORT . . . . . . . . . . . . . . 1

2. COMPUTER MODEL SELECTION ...................... 3

2.1 REQUIRED MODEL CHARACTERISTICS . . . . . . . . . . . . 3

2.2 CLASSIFICATION OF EXISTING MODELS . . . . . . . . . 3

2.2.1 Empirical/Analytical Models ............ 3

2.2.2 Simulation Models . . . . . . . . . . . 4

2.2.3 Hybrid Models: Life-Cycle Simulators ....... . 4

2.3 CHARACTERISTICS OF EXISTING SIMULATION MODELS . . . . . . 5

2.3.1 Virginia Polytechnic Institute Mode1 . . . . . . 5

2.3.2 Pennsylvania State University Model . . . . . . . 5

2.3.3 Twin Cities Mining Research Center Mode1 . . . . . 6 .

2.3.4 Bureau of Mines Costing Information Circulars . . . 6

2.3.5 NUS Corporation Mode1 . . . . . . . . . . 6

2.4 DESCRIPTION OF ADAM/ 1 MODEL . . . . . . . . . . . . . . 7

2.4.1 Access to the Model . . . . . . . . . . . 9

2.4.2 Application Demonstration . . . . . . . . . 10

2.4.3 Accuracy .................. 10

2.5 SUMMARY . . . . . . . . . . . . . . . . . 10

3. EVALUATION OF ADAM/1 MODEL ....................... 11

3.1 TEST CASE SELECTION . . . . . . . . . . . . . . . 11

3.2 NOTE OF CAUTION ..................... 11 
3.3 SUMMARY OF RESULTS . . . . . . . . . . . . . . 12

3.3.1 Hydraulic Borehole Mining . . . . . . . . 12

3.3.2 Spiral Longwall Mining ... . . . . . . . 12

3.4 TIME AND COST . . . . . . . . . . . . . . . . 16

4. CONCLUSIONS AND RECOMMENDATIONS . . . . . . . . . . . . . . 17

BIBLIOGRAPHY . . . . . . . . . . . . . . . . . . . . 19

\section{Figures}

1. Overall Organization of ADAM/1 Model ........... 8

2. Conceptual Borehole Hydraulic Mining System . . . . . 13

3. Spiral Longwall Panel Schematic . . . . . . . . . 14

\section{Tables}

1. ADAM/l Results for Spiral Longwall . . . . . . . . . 15

\section{At tachment}

The INPUT/OUTPUT printout for the two test cases run is sent to DOE as an attachment to the present report. Copies of this attachment are available, upon request, from the authors till December 31, 1982. 


\section{SECTION 1}

\section{INTRODUCTION}

\subsection{BACKGROUND}

The Advanced Coal Extraction Project is sponsored by the Department of Energy (DOE) at the Jet Propulsion Laboratory (JPL) to define and develop advanced underground coal extraction systems which: (1) are suitable for significant remaining resources after the year 2000, and (2) promise a significant improvement in production cost and miner safety, with no degradation in miner health, environmental quality and resource recovery. System requirements in the five performance areas have been defined by Goldsmith and Lavin (1980).

One of the project tasks requires the development and refinement of techniques for projecting and evaluating the performance of these advanced coal mining systems in each of the above five areas. Thus far, formal


health ( $Z$ immerman, 1980); environmental quality (Dutzi, et al., 1980 and Sullivan and Lavin, 1981); and conservation (Goldsmith and Lavin 1980 and O'Toole and Walton, 1980).

Several models have been developed to analyze the production costs and economics of mining systems. Life-cycles in existing mine systems and their costs were studied by (Lavin, et al., 1978 and Mabe, 1979). The effect of subsystem interactions was modeled by Lohman (1978). A moving baseline system cost model was established by Bickerton and Westerfield (1981) by projecting the performance of existing systems and anticipated improvement to the year 2000. Finally, regional price targets for coal produced by the year 2000 were developed by Terasawa and Whipple (1980).

This document summarizes the results of evaluating a computer simulation model for capacity characterization and for the determination of production costs of non-conventional mining systems.

\subsection{OBJECTIVES}

The objectives of the effort described in this document are: (1) to select a computer model which can be used to estimate life-cycle costs either at system level or at subsystem level, and (2) to demonstrate its. applicability to performance and cost evaluation of unconventional systems by running two test cases.

\subsection{ORGANIZATION OF THE REPORT}

Section 2 presents a summary of the reasoning behind the selection of the ADAM/ 1 mode1. Section 3 covers the two test cases run leading to the conclusions presented in Section 4. Since the ADAM/1 model and its documentation are available commercially, the data instruction set is not presented in this report. 


\section{THIS PAGE \\ WAS INTENTIONALLY \\ LEFT BLANK}

2 
SECTION 2

COMPUTER MODEL SELECTION

\subsection{REQUIRED MODEL CHARACTERISTICS}

A satisfactory computer simulation model for use in conjunction with an Advanced Coal Extraction System must meet the following requirements.

(1) The model must have the capability to determine the productive capacity of the system as well as its life-cycle production costs.

(2) The model must be able to handle unconventional equipment and mining procedures.

(3) It should allow evaluation of subsystem performance.

(4) It should be simple to use.

(5) The model should be reasonably acceptable to the mining community.

Six computer models were reviewed against these requirements. All were known to the industry and indeed were being applied, to varying degrees, for mine design and evaluation, thus, meeting the fifth requirement.

Soon after starting the evaluation process, it became apparent that models which simulated life-cycles of mining systems would directly meet our requirements. This led to the selection of the ADAM/l model. A classification of merits and drawbacks of available models is presented in the next section. Individual models examined are described in section 2.3.

\subsection{CLASSIFICATION OF EXISTING MODELS}

Available computer-based models for mining system evaluation can be classified into three groups which are described briefly below.

\subsubsection{Empirical/Analytical Models}

The empirical models are based upon the analysis of a large number of field observations. First, the relationships between geological variables, e.g., seam thickness, depth; mining configurations, e.g., method, equipment, sequence; and managerial variables e.g., annual production, mine life, manpower, and capital requirements, are observed at a number of operating mines. Then, using regression methods, an overall 1 ife-cycle cost model is developed from these data. Within the bounds of the validity of the data, the results can be fairly accurate.

The EPRI/NUS model (Toth, 1977) and one of the USBM models (Duda and Hemingway, 1976; and Katell, et al., 1976) are examples of this empirical/analytical approach. 
Unfortunately, for each new method or for each new mining system, new data must be collected and new analytical relationships must be derived. For example, the NUS Corporation could not use their coal cost model for in situ solution mining; instead, they had to develop a new model for that application (Toth and Chase, 1978). Further, in cases where data from existing mines using the technique under consideration are not available, as would be the case for almost all advanced systems, the technique cannot be used at all. Finally, these models are not suitable for subsystem evaluation. Thus, these models fail to meet two of our requirements.

\subsubsection{Simulation Models}

Industrial engineering was introduced to underground coal mining applications in the $1960 \mathrm{~s}$. The first such model was developed at Virginia Polytechnic Institute (VPI), by Prelaz et al., (1964). A time-motion oriented model was later developed at Pennsylvania State University (PSU) by Manula and Rivell (1974). Other models currently being used in the industry are derived from either of these two models.

Mining consists of various, sequences of activities. The PSU model uses statistical information on performance rates of machines (e.g., tramming and cutting rates) and mining activities (e.g. safety inspection) to create possible sequences of mining operations over a period of one or more shifts. The production data averaged over a number of shifts represents a probable production picture for the mine under consideration.

Mabe (1979) and Lavin et al., (1978) have looked into the use of these models. In addition, one of the authors, M. Gangal, had supervised the use of both of the models. The consensus is as follows:

- These models are extremely useful in optimizing production decisions.

- The programs are tied closely to existing systems.

- Data inputs to these programs are rather cumbersome.

- It is possible to modify the programs for use with advanced systems; but that would require substantial work. Indeed, the PSU model can be used as a subprogram of the program described in the next section.

In conclusion, with suitable modification, these models can be used for our application. However, since a model which directly met all the requirements was available, a decision was made to drop VPI and PSU models as a primary approach.

\subsubsection{Hybrid Models: Life-Cycle Simulators}

Micro-simulation and life-cycle costing can be combined. The resultant model simulates life-cycles of mining systems under constantly varying conditions. The ADAM/ 1 model uses this approach. It combines micro and 
macro level simulators and a user-defined strategy tree to develop life-cycle cost projections. The model can be used either at the system level or at the level of a subsystem to determine the relevent life-cycle costs.

The ADAM/1 model was developed by Ketron Inc. for a number of potential applications including, comparisons of equipment technologies, mining systems, and mining strategies. As independent contractors for DOE, Skelly and Loy (1980), evaluated the model and found it to be satisfactory. It appeared that this type of model would meet our requirements; hence, it was decided to further evaluate this approach.

\subsection{CHARACTERISTICS OF EXISTING SIMULATION MODELS}

The simulation models noted in Section 2.2 .2 are briefly described below. All of the model descriptions are extracted directly from Mabe (1979) and reproduced here for the convenience of the reader.

\subsubsection{Virginia Polytechnic Institute Mode1 (VPI)}

(See Prelaz, et al., 1964)

"In an effort to understand and improve the efficiency of the modern, complex, coal mining systems, the Office of Coal Research sponsored a research project at VPI. Starting in April of 1962, the project was to devise a method whereby the factors which influence mining costs in the immediate production area could be identified. The project was the first such effort and was based on the simulation techniques developed in other industries that use the specialized characteristics of high-speed digital computers.

"Two computer programs were developed to simulate activity on a production section. One program was designed specifically to accommodate intricate mining systems and to analyze systems using as many as twelve mining machine units and a maximum of six shuttle cars. The other program was designed to evaluate mining systems in which a maximum of three shuttle cars are used in conjunction with a continuous miner. These programs are event=oriented in theii construction."

\subsubsection{Pennsylvania State University Model}

(See Manula and Rive11, 1974)

"The continuing need on the part of mine management for a decision-making tool to replace the costly trial and error method led to a contract between the U.S. Bureau of Mines (USBM) and Pennsylvania State University to develop "A Master Environmental Control and Mine Systems Design Simulator for Underground Coal Mining." This contract led to the development of a computer-based simulation model that ties together environmental impacts, geological conditions, materials handling operations, support functions, mining methods, and economics into a comprehensive package for planning, designing, and controlling new or existing coal mining operations. The operation of an entire mine can be simulated via the time-increment method of simulation. In addition to analysis of productivity and cost, this simulation can also be used to study possible impacts on mine health and safety." 


\subsubsection{Twin Cities Mining Research Center Model}

"The Bureau of Mines Twin Cities Mining Research Center developed a flexible mining simulation model that can handle a variety of mining methods. This effort was undertaken to provide a simulation system that could be easily applied to describe the mining of coal, salt, copper, etc., without making internal changes to the simulation model (as would be required by the VPI and Penn State models), if they were to be used to model anything other than underground coal mining. The Bureau of Mines model contains the elements common to all production systems: activities or events, equipment, and inventories. Procedures were developed to represent a wide range of interaction between those elements in order to accommodate complex operations. The model has been used for longwall and room and pillar applications to determine the economical feasibility of mining methods within certain geological constraints."

\subsubsection{Bureau of Mines Costing Information Circulars}

(See Duda, et al., 1976 and Kate11, et al., 1976)

"In 1974, the United States Bureau of Mines began issuing a series of information circulars that provide a framework for estimating capital investment and operating costs for coal mines. These studies are meant to assist mine operators in planning new mining operations and are organized around familiar cost summaries: investment in construction, equipment and working capital; manning tables; breakdown of operating costs; treatment of federal and state taxes, including the impact of depletion and depreciation; expenditures on consummables, etc. Capital charges are discounted by the present mine investment. The authors then calculate the selling price of "run-of-the-mine" coal, assuming constant sales for the life of the mine that amortize the investment, cover the annual operating costs, and allow for an adequate profit. These circulars present a method for capital budgeting that is easily understood, comprehensive, and can be quite useful to the mine operator."

\subsubsection{NUS Corporation Mode1}

(See Toth, 1977)

"The NUS Corporation developed an underground coal mining cost model for the Electric Power Research Institute (EPRI). Designed to analyze costs of individual coal mines and to generate minimum acceptable selling prices, this model transforms the Bureau of Mines economic calculations into a computer format. In addition, it has the capability of relating section production to projections for seam thickness, overburden, roof and floor quality, pitch, and methane. Detailed equipment, construction, supplies, and labor costs are stored in the computer and manipulated, as necessary, to calculate the required costs. Section production is obtained from tables which were derived via correlation of empirical and simulation production data on the effect of various combinations of geological conditions. 
"The wide range of variables which can be accommodated by the cost model facilitates its application to mining situations encountered in any coal producing region of the United States. Optional data inputs are provided to facilitate changes in numerical values. This feature also allows the cost of machinery, construction, labor, etc., to be updated, using cost index projections. Although the model has 1975 cost numbers stored for normal use, year 2000 cost numbers can be generated easily via the optional input feature."

\subsection{DESCRIPTION OF ADAM/ 1 MODEL}

The Advanced Development Analysis Model (ADAM/1) consists of a series of computer models and associated files which provide the users with a powerful analytical tool for evaluating the production and cost consequences of specific mine designs, production strategies, and equipment selections. This model was developed by Ketron, Inc. Much of the description presented below is excerpted from Ketron reports and brochures (Kohler, et a1., 1980). The overall organization of $\mathrm{ADAM} / 1$ is shown in Figure 1.

ADAM/l allows detailed analysis of up to 25 separate mine elements such as mains, submains, entryways or sections; each of which may be further uniquely defined by its mining plan, dimensions, advance rate, production rate, equipment requirements, and operating costs. A mining plan may consist of up to 1000 individual segments, which may be grouped into each of the 25 mine element types.

A maximum of 250 operating cost items may be detailed for the mine including direct labor, salaried labor, operating supplies, maintenance supplies, roof bolts, rock dust, hydraulic oil, miner bits, etc. Such costs may be detailed within any one or all of the mine elements. Thus, the user may focus on subsystem life cost evaluation or look at the whole system in detail.

The user begins by preparing a trial design of his mine. Although this need not be a detailed design, general mine layout and opening dimensions must be realistic for the mining property.

A strategy tree is then constructed, made up of mining elements and segments. Two important parameters which describe segments and elements are advance rate (feet per shift) and production rate (tons per shift), which may either be supplied by the user or may be computed using the Critical Path Processor Routine in the program. The latter option can be used for capacity characterization of advanced systems and subsystems, and is described below in more detail.

The Critical Path Processor is used in the following manner. The user defines one cycle of the coal extraction plan by an expanded single-cycle network ( $C P N)$. The CPN is a set of interconnected activities required to complete the extraction of a panel of coal. Each activity has a specified start and end point (called start and end nodes), and the network defines the logical interaction, such that certain activities cannot proceed until others are finished. This single-cycle network is later used to construct a higher level critical path network. 




Figure 1. Overall Organization of ADAM/I Model 
For the information of the reader, the "critical path" is defined as a path through the network which has no slack time, so that each succeeding activity must be initiated immediately following the completion of all predecessors. Any delays along this path will induce an overall project delay, whereas delays along other paths can be absorbed within the available slack time. Using the CPN, the program calculates the number of shifts along the critical path and then computes the advance and production rate, for the mine element under consideration.

Once the mine element parameters have been defined, the mine strategy tree is processed by the Tree Processor routine. Each individual segment is executed in sequential order after the following two conditions are met:

(1) All predecessor nodes of the tree (fathers) are complete.

(2) The equipment required for the next segment's type is available.

If either of the above conditions are not met, the segment is put into a first-in-first-out (FIFO) queue to be serviced when the appropriate deficiency has been fulfilled. From this analysis the annual mine production and equipment request reports are printed. A total mine level summary is then provided after all segments in the mine tree have been executed.

User-supplied cost inputs are combined with Tree Processor outputs to create the files required by the Life Cycle Financial Analysis Subprogram whose outputs produce the following final reports:

(1) Capital Costs.

(2) Production and Revenues.

(3) Cash Operating Costs.

(4) Non-Cash Operating Expenses.

(5) Operating Cost per Ton per Year.

(6) Net Profit per Year.

(7) Discounted Cash Flow per Year.

(8) Net Present Value, Present Value Ratio, Investment Rate of Return, and Payback Period.

\subsubsection{Access to the Mode1}

The model is available on the General Electric Information Systems Network. It is maintained by Ketron Inc., and updates and any routines added in the future will be automatically available to all users. Commercial availability was considered to be a positive feature of this model. 
Since the model and its documentation are available, commercially, input instructions are not presented here. For further information, the reader should contact: Ketron Inc., 530.E. Swedesford Road, Wayne, PA 19087.

\subsubsection{Application Demonstration}

Under a contract from DOE, Ketron, Inc., studied six advanced mine plans and development techniques using ADAM/L life-cycle simulator (Kohler, et al., 1980). An in-depth examination of the report confirmed the merits of applying the program for evaluting advanced concepts.

In some of the cases reported, retreating longwall technique was used in conjunction with single entry development (an advanced technique). (This showed that the model can be used to determine the life-cycle impact of a new subsystem.)

\subsubsection{Accuracy}

There is no simple method of determining the accuracy of mine simulation programs. For a given mine, mining engineers can hand calculate the projected average performance at that mine. Kohler, et al., (1980), reported that ADAM/1 results were within $15 \%$ of the hand calculations.

An independent evaluation for DOE, by Skelly and Loy (1980), showed that the engineering consulting firm judged the program to have satisfactory results.

\subsection{SUMMARY}

In conclusion, then, the ADAM/l model appeared to meet all of our requirements. To ensure that the model will be useful to analyze systems and subsystems which are totally unlike present systems, two test cases were run. The purpose of these tests and the results are described in the next section. 
SECTION 3

EVALUATION OF ADAM/ 1 MODEL

\subsection{TEST CASE SELECTION}

The advanced coal extraction project will be examining a wide variety of systems which can be classified into two groups: (1) in situ systems which are usually operated from the surface, and (2) in-mine systems which require the presence of miners in the mine cavity to operate and/or to supervise equipment. It was determined that one test case from each of the two classes should be run using ADAM/l.

\section{Case 1: Borehole Mining}

USBM has been interested in applying borehole mining techniques for underground coal mining. At JPL, Floyd (1977) has done a rather complete and careful evaluation of the system using a detailed (hand) calculation procedure.

Running one of Floyd's cases would be useful in two ways: (1) it would show that the ADAM/l model can handle equipment, mine configuration, and mining strategies which are totally unlike the conventional mining systems; and (2) it would allow us to estimate the accuracy of the program against Floyd's analysis, in which we have confidence. Hence, a borehole mining case was selected for ADAM/l evaluation.

Case 2: Spiral Longwall

Goettig (1978) reported on the use of advancing turning longwalls in German coal mines. Roye (1978) patented a circle-cutting radial mining system, which is based upon a similar turning longwall concept.

From these two, we made up the concept of spiral longwall as an example of advanced mine planning and operation. The spiral longwall uses the same equipment and manpower as today's longwall system, but uses different mine layout and procedures for development. This case, then, would allow us to see the ability of ADAM/l to handle changes in the planning and development subsystems.

\subsection{NO'E OF CAUTION}

The purpose in running the two test cases was to test the abilities of the computer model and not to examine the merits of the particular cases run. Thus, the reader must curb his temptation to interpret the results in terms of feasibility of the borehole and spiral longwall concepts. Indeed we do not even know if either can work under real life conditions. To emphasize this point we restate the following:

"THE TEST RESULTS CANNOT, EVEN BY REMOTE INFERENCE, BE USED TO DETERMINE THE TECHNICAL AND ECONOMIC FEASIBILITY OF THE BOREHOLE MINING AND SPIRAL LONGWALL SYSTEMS. RATHER, THEY SHOULD BE USED TO ESTIMATE THE SUITABILITY OF THE ADAM/1 MODEL TO EVALUATE ADVANCED SYSTEMS." 


\subsection{SUMMARY OF RESULTS}

\subsubsection{Hydraulic Borehole Mining}

Figure 2 shows the proposed mining system configuration schematically. In this method, the coal seam is accessed through holes drilled from the surface. After drilling the hole, a device embodying a water jet cutter and a down hole slurry pump is lowered into the access hole. High pressure water, pumped from the surface, is discharged through the rotating, high pressure jet nozzle cutters near the lower end of the device. The jets fragment the coal, and form a slurry at the bottom of the underground cavity which is then drawn into the mining device by the pump, and lifted to the surface. The downhole slurry pump is driven by high pressure water supplied by a second set of pumps on the surface. The mining device, as presently conceived, consists of chambers and conduits, built within a 12-in. tubular housing, which channels the water to the cutting nozzles and the jet pump. A working prototype model of the hydraulic borehole mining device has been designed, fabricated, and tested by Flow Research, Inc., under contract to the Twin Cities Bureau of Mines Research Center.

Floyd (1977) studied the Borehole Hydraulic Mines (BHM) in depth for various seam thicknesses and various depths of cover. One specific case from his report is used here as a test case. The selected seam thickness is $30 \mathrm{ft}$ and the cover depth is $200 \mathrm{ft}$. Under these conditions Floyd predicted the BHM to produce coal at a selling price of $\$ 27.11$ per ton of coal at $15 \%$ rate of return on investment. The production rate was assumed to be 40 tons per hour.

The borehole mining sequence is quite repetitive: drill access holes, cut coal and pump it out, close the cavity, and move to the next spot. A version of ADAM/ 1 used for simulating oil shale mining was found to be very useful for coding the recurrent sequences of BHM. Various operating rates, manpower, equipment costs, sequence of events, utilities, and expendable costs were the inputs to the model; all specified from Floyd's data.

The use of the detailed networking techniques of ADAM/l brought out several operating delays which were ignored in Floyd's simplified hand analysis. Because of the newly discovered delays, the price projected by the computer simulation model was slightly higher than Floyd's result. The model predicted the price of coal at $\$ 28.32$ per ton compared with the hand calculated value of $\$ 27.11$ per ton. This result was judged to be very satisfactory in terms of accuracy. The running of this test case gave us confidence that the model can handle unusual equipment, manning arrangements, and procedures:

\subsubsection{Spiral Longwall Mining}

Delays in moving longwalls, from one panel to another, have always been a problem. It appeared that these could be minimized by using a German developed turning longwall technique applied in simple geometric arrangements, circular and spiral. Figure 3 shows the schematic of a spiral longwall plan used in the example. The production rate from this type longwall changes at every turn. Thus, adapting to the changing lengths of the segments and related changes in. the production rate would put the networking capability of ADAM/l to test. 

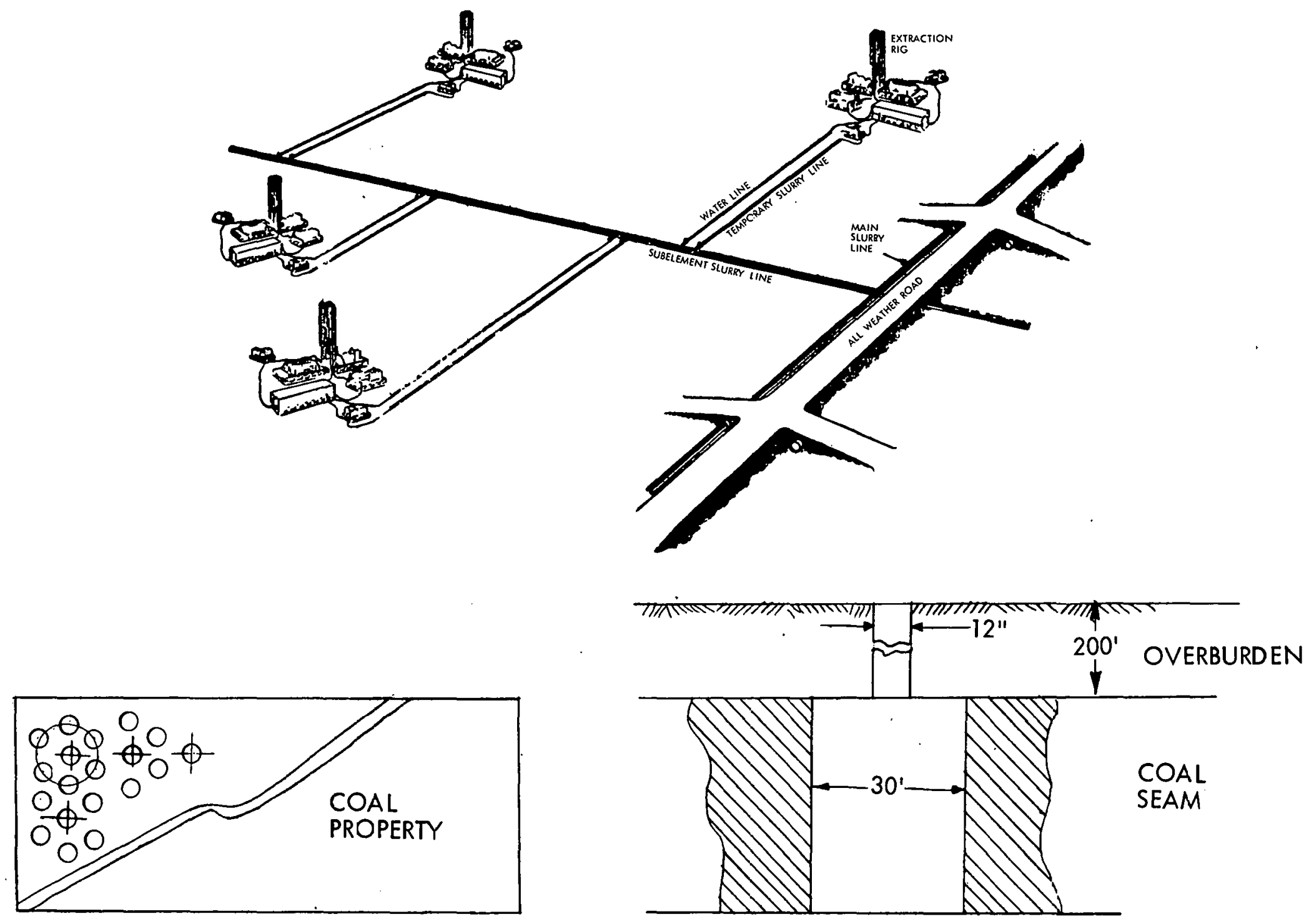

Figure 2. Conceptual Borehole Hydraulic Mining System 


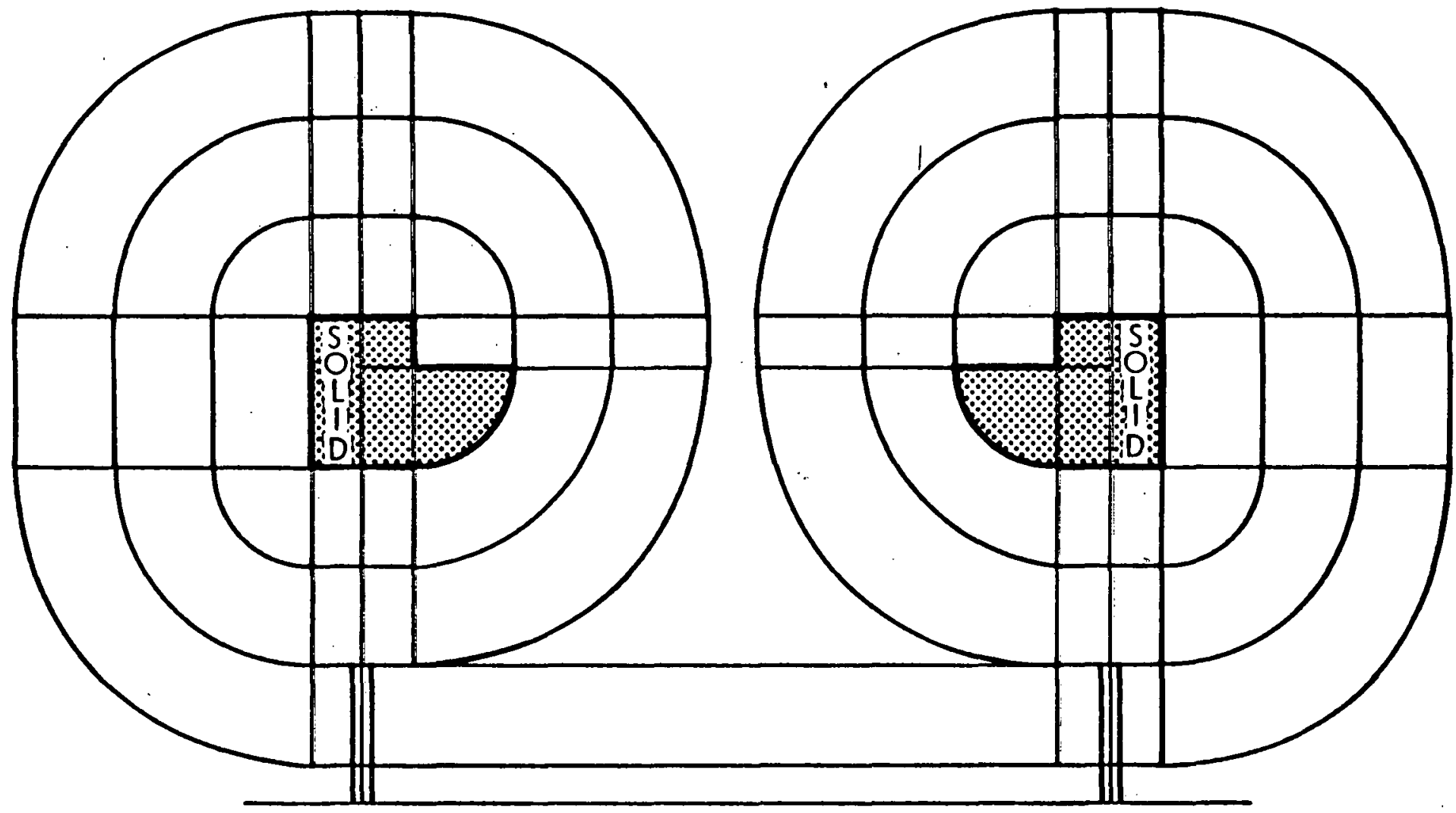

Note: The concept of the spiral longwall is so new that mining feasibility has not been established. Therefor?, the above sketch should be used for no other purpose than to illustrate the geometric pattern.

Figure 3. Spiral Longwall Panel Schematic 
Spiral longwall as a concept has never been considered seriously. Actually, we doubt seriously if the technical problems with it can be solved at all. Nevertheless, its use as a test case is well worth the effort for the reasons outlined above.

It is not easy to compare the results obtained for the spiral longwall case since there is no comparable experience. Fortunately, Bickerton and Westerfield (1981) had calculated performance of longwall systems under average and ideal conditions (see Table 1). Under ideal conditions, longwall delays are minimized; thus, it is believed that the spiral longwall calculation should produce results comparable to ideal longwall.

It was quickly realized that the comparison with Bickerton and Westerfield (1981) would not be quite so straightforward. Since spiral longwall needs much less development, its capital requirements would be significantly lower than those of a standard longwall mine. To compensate the effects, in the test case, the mine life was reduced to eight years, enough to complete one sequence of spirals, and the discount rate was increased to $25 \%$; both were judgmental values. This contrasts with Bickerton's values of 20 years 1 ife and $15 \%$ discount rate. Since the analysts tend to make self-fulfilling assumptions, the reader is cautioned not to attach too much meaning to the quantitative results.

The costs associated with spiral longwall mining and coal cutting rates were based on currently available equipment. Labor requirements were similar to longwall mining. The seam thickness was assumed to be 96 in. The results of the analysis are shown in Table 1 . It appears that the ADAM/1 calculations are "in the same ball park" as ideal longwall computations.

Table 1. ADAM/l Results for Spiral Longwall

\begin{tabular}{cccc}
\hline System & Condition & $\begin{array}{c}\text { Tons Per } \\
\text { Machine } \\
\text { Shift }\end{array}$ & $\begin{array}{c}\text { Projected } \\
\text { Selling Price } \\
\text { \$/Ton }\end{array}$ \\
\hline $\begin{array}{c}\text { Retreating LW } \\
(\text { Ref. 8) }\end{array}$ & Average & 830 & $\$ 29.05$ \\
$\begin{array}{c}\text { Retreating LW } \\
(\text { Ref. 8) }\end{array}$ & Ideal & 1770 & $\$ 17.50$ \\
$\begin{array}{c}\text { Spiral LW } \\
(\text { ADAM/1) }\end{array}$ & $\begin{array}{c}\text { Straight } \\
\text { \& Bends }\end{array}$ & $1275-$ & $\$ 17.09$ \\
\hline
\end{tabular}

More important than the quantitative result was the fact that ADAM/1 was able to handle constantly changing mining systems and was able to integrate a new plan within the framework of an otherwise conventional system. 


\subsection{TIME AND $\operatorname{cosT}$}

In each test case, it took an effort of one workday for input data preparations by an expert. Assuming that it takes two or three days of a non-expert's time to do the same work, the data preparation costs appear to be reasonable.

Computer time and costs were negligible in the two examples. However, in the future, when the program is applied to completely designed systems, many more detailed computations would have to be performed and costs would go up. Even then, on the basis of the Skelly and Loy (1980) test, costs appear to be reasonable. Exact values will, naturally, depend upon the size of the - problem and the finesse of output information desired. 
Section 4

\section{CONCLUSIONS AND RECOMMENDATIONS}

ADAM/1 Model was selected for use on the advanced coal extraction project on the basis of the requirement for life-cycle costing capabilities and the ability to handle subsystems.

The model was tested by simulating two totally new mining concepts. The results were satisfactory, therefore, a recommendation is made to the Advanced Coal Extraction Project, to use ADAM/l for System Evaluation Studies during the Conceptual Design Phase.

On the basis of only these two tests, one cannot be absolutely certain that the model is capable of simulating all conceptual mining techniques; but it appears that it can handle most systems under consideration in the project at this time. In case the project plans to use the program frequently, modifications to the model to improve the output format of the financial summaries and an addition of a more general micro-level simulation of new mining concepts should be considered. 
THIS PAGE

\section{WAS INTENTIONALLY LEFT BLANK}


Bickerton, C. R., and Westerfield, M. D., A Moving Baseline for Evaluation of Advanced Coal Extraction Systems, Jet Propulsion Laboratory Publication No. 81-31, Pasadena, CA, 1981 .

Duda, J. R., and Hemingway, E. L., Basic Capital Investment and Operating Costs for Underground Bituminous Coal Mines Developed by Longwall Mining:

- Mines with Annual Production of 1.3 and 2.6 Million Tons from a 48-inch Coalbed," Bureau of Mines Information Circular 8715 (1976).

- Mines with Annual Production of 1.5 and 3 Million Tons from an 84-inch Coalbed," Bureau of Mines Information Ci.rcu?ar 8715 (1976).

Dutzi, E. J., et al., The Environmental Assessment of a Contemporary Coal Mining System, Jet Propulsion Laboratory Publication No. 80-99, Pasadena, CA, 1980 .

Floyd, E. L., Borehole Hydraulic Coal Mining System Analysis, Jet Propulsion Laboratory Publication No. 77-19, Pasadena, CA, 1977.

Goettig, P., "Advancing Longwall and 180 Move to Next Panel," Mine Manager, Ahlen, West Germany, Rocky Mountain Coal Mining Institute, 1978.

Goldsmith, M., and Lavin, M. L., Overall Requirements for an Advanced Underground Coal Extraction System, Jet Propulsion Laboratory Publication No. 80-39, Pasadena, CA, 1980.

Katel1, S., Hemingway, E. L., and Berkshire, L. H., Basic Capital Investment and Operating Costs for Underground Bituminous Coal Mines:
- Mines with Annual Production of 1.03 to 3.09 Million Tons from a 48-inch Coalbed," Bureau of Mines Information Circular 8689 (1976).
- "Mines with Annual Production of 1.06 to 4.99 Million Tons from a 72-inch Coalbed," Bureau of Mines Information Circular 8682A (1976).

Kohler, J. L., et al., Impact of Advanced Development Techniques on Mine Design, Draft Fina1 Report, DOE Contract No. ET-77-C-01-8915(9), 1980.

Lohman, G. M., A Closed Network Queue Model for Underground Coal Mining Production, Failures, and Repairs, Jet Propulsion Laboratory Publication No. 78-72, Pasadena, CA.

Lavin, M. L., Borden, S. C., and Duda, J. R., A Life-Cycle Description of Underground Coal Mining, FE/9036-1, U.S. Department of Energy, 1978 .

Lucas, J. R., Bucklen, E. P. and Prelaz, L. J., "A New Cost Reduction Tool for the Coal Industry," Mining Engineering, 1965. 
Mabe, W. B., Economic Baselines for Current Underground Coal Mining Technology, Jet Propulsion Laboratory Publication No. 79-122, Pasadena, CA, 1979 .

Manula, C. B., and Kenzy, G., "Predicting Productivities and Capital Equipment Requirements Using the PSU/USBM Coal Mine Simulator," World Mining and Metals Technology, American Institute of Mining, Metallurgical and Petroleum Engineers, NY, 1976.

O'Toole, R. P., and Walton, A. L., Integenerational Equity and Conservation, Jet Propulsion Laboratory Publication No. 80-49, Pasadena, CA, 1980.

Ramani, R. F., and Manula, C. B., A Master Environmental Control and Mine Systems Design Simulator for Underground Coal Mining, Report Prepared under USBM Grant No. G0111809, 1975.

Skelly, and Loy, An Evaluation of Ketron's Underground Mining Model Called ADAM, U.S. Department of Energy Contract No. DE-AC01-79ET11268, Final Report, 1980.

Sullivan, P. J., and Lavin, M. L., Environmental Cost of Underground Coal Technology, ASCE Conference, Energy: The Man-Built Environment, Vail, CO, 1981 .

Terasawa, K. L., and Whipple, D. W., Regional Price Targets Appropriate for Advanced Coal Extraction, Jet Propulsion Laboratory Publication No. 80-91, Pasadena, CA, .1980.

Toth, G. W., Coal Mining Cost Models, Volume 1: Underground Mines, NUS Corporation, Project 435-1, EPRI, Palo Alto, CA, 1977.

Zimmerman, W. F., Health Requirements for Advanced Coal Extraction Systems, Jet Propulsion Laboratory Publication No. 80-72, Pasadena, CA, 1980.

Zimmerman, W. F., Safety Evaluation Methodology for Advanced Coal Extraction Systems, Jet Propulsion Laboratory Publication No. 81-54, Pasadena, CA, 1981. 